\title{
Morphological, cytological and molecular marker analyses of 'Tapestry' caladium variants reveal diverse genetic changes and enable association of leaf coloration pattern loci with molecular markers
}

\author{
Zhe Cao $^{1}$ (D) Zhanao Deng $^{1}$ (1)
}

Received: 10 April 2020 / Accepted: 21 August 2020 / Published online: 3 September 2020

(c) The Author(s) 2020

\begin{abstract}
Somaclonal variation and induced mutation are highly valuable sources of genetic variation for genetic improvement and research in horticultural crops; cellular and molecular characterization can greatly facilitate their uses in these areas. In the present study, 20 caladium variants were identified among 'Tapestry' plants that were regenerated from leaf cultures treated with or without colchicine. These variants showed changes in leaf main vein color and coloration pattern and were separated into ten groups based on leaf morphological changes. Five variants contained 3.3-9.7\% more nuclear DNA than the wildtype and gained one, two or three chromosomes, while four variants contained 3.0-4.8\% less nuclear DNA and lost one chromosome. Five, out of 22, simple sequence repeat-based molecular markers detected DNA banding pattern changes in 13 of the 20 variants. Two molecular markers (CaM24 and CaM62) detected DNA banding pattern changes in the same four variants, suggesting that these two markers may be located in the same chromosomal segment. Strong association between leaf characteristics (leaf blotching and main vein color) and molecular banding pattern changes with molecular marker CaM42 were observed in six variants, indicating that CaM42 may be associated with gene loci controlling leaf blotching and leaf main vein color in caladium.
\end{abstract}

\section{Key message}

Detailed characterization of 'Tapestry' caladium variants revealed changes in nuclear DNA content, chromosome number and molecular marker banding pattern and associated gene loci controlling leaf characters with molecular markers.

Keywords Caladium $\cdot$ Chromosome loss $\cdot$ Chromosome gain $\cdot$ Nuclear DNA content $\cdot$ SSR banding pattern change

\section{Abbreviations}

BA 6-Benzyladenine

CCI Caladium callus induction

Communicated by M. I. Beruto.

Electronic supplementary material The online version of this article (https://doi.org/10.1007/s11240-020-01922-2) contains supplementary material, which is available to authorized users.

Zhanao Deng

zdeng@ufl.edu

Zhe Cao

cjun01@gmail.com

1 Department of Environmental Horticulture, Gulf Coast Research and Education Center, University of Florida, IFAS, 14625 County Road 672, Wimauma, FL 33598, USA
CTAB Cetyl trimethylammonium bromide

FCM Flow cytometry

NAA 1-Naphthyl acetic acid

MS Murashige and Skoog's medium

PE-2 Plantlet enhancement medium

SD Standard deviation

SSR Simple sequence repeat

VT Somaclonal variant type

\section{Introduction}

Genetic variation/mutation is essential and vitally important for genetic improvement and development of new cultivars in crops. One important type of genetic variation is somaclonal variation that is induced during in vitro cell, tissue and organ 
culture (Larkin and Scowcroft 1981). Somaclonal variants have been reported in numerous plants, and they can exhibit significant variability in morphological characters, physiological traits, and resistance or tolerance to biotic or abiotic stresses compared to the original (mother) plants from which the cells and tissues were taken for in vitro culture (Heinz et al. 1977; Selby and Collin 1976; Sunderland 1977; Trujillo and Garcia 1996). Somaclonal variation has been used to create new phenotypes or cultivars in numerous crops. For example, cultivars with different ripening time and improved fruit quality have been developed from somaclonal variants of sweet orange (Citrus sinensis), a citrus species whose genetic diversity is extremely low and difficult to generate through sexual hybridization (Grosser and Gmitter 2016). A number of disease-resistant apple rootstock and banana cultivars have been selected out of somaclonal variants [reviewed by Krishna et al. (2016)]. Somaclonal variation can be even more useful and valuable in ornamental plant breeding, as new morphological change in these plants may be considered as new phenotypes with increased aesthetical values. In ornamental aroids alone, somaclonal variations have resulted in nearly 80 new cultivars in Aglaonema, Alocasia, Anthurium, Calathea, Dieffenbachia, Philodendron, Spathphyllum, and Sygonium (Chen et al. 2003; Chen and Henny 2008; Henny et al. 2003).

In addition to producing somaclonal variation, in vitro cultures have played another important role in inducing mutation for genetic improvement of plants (reviewed by Maluszynski et al. 1995). The availability of in vitro cultures and culturing methods has enabled mutagenic treatment of large populations of cells, in vitro selection for desirable mutants, rapid production of mutant plants, and/or overcoming of chimerism, a difficult issue frequently encountered when plant tissues and organs were mutagenized and propagated in vivo (Van Harten 1998). For example, efficient culturing techniques have allowed large numbers of uninucleate microspores of rapeseed to be treated with mutagens followed by somatic embryogenesis, in vitro selection, and production of solid mutants with herbicide tolerance (Swanson et al. 1989). Because of sterility, banana cannot be improved through conventional breeding techniques. The combination of in vitro culturing and mutation induction techniques have resulted in mutants with much improved tolerance to Fusarium wilt, a destructive diseases of banana (Jain 2008). The term in vitro mutation induction or in vitro mutagenesis has been used to recognize the significant value of such a combination or integration of techniques (Sonnino et al. 1985). In vitro mutation induction techniques have been applied to ornamental plants (Datta and Teixeira da Silva 2006), but to a very limited extent, especially in aroid plants.

Caladium (Caladium $\times$ hortulanum Birdsey) is an important ornamental plant belonging to the Araceae (aroid) family. The main approach for new caladium cultivar development has been through sexual hybridization between existing commercial cultivars and breeding lines (Cao et al. 2014; Deng et al. 2007; Deng 2012; Wilfret 1993). After decades of intense caladium breeding and selection, finding novel leaf characters has become very difficult (Deng 2012). This difficulty is due to the restricted variability in the current germplasm. Therefore, new sources of genetic variation are in dire need for caladium breeding (Deng 2018).

Since tissue culture was first reported in caladium in 1974 (Hartman and Zettler 1974), a number of reports have indicated that somatic variation is common in some caladium cultivars. For example, up to $80 \%$ of the regenerated plants of several caladium cultivars showed obvious phenotypic changes compared to the original stock plants (Ahmed et al. 2004; Chu and Yazawa 2001). Phenotypic changes in caladium somaclonal variants seem to mainly involve leaf characters (Ahmed et al. 2002, 2004; Thepsithar et al. 2010; Thongpukdee et al. 2010). The occurrence of somaclonal variation in caladium seems to be dependent on the use of plant regulator, explant type and plant genotype. Reportedly the use of 2,4-dichlorophenoxyacetic acid and old plant tissue could increase the occurrence of somaclonal variation (Ahmed et al. 2002, 2004; Cao et al. 2016; Chu and Yazawa 2001). However, few of these reported variants have been characterized at the cytological or molecular level. The lack of cytological and molecular genetic characterization of these variants has hindered broader adoption of somaclonal variation as a new approach for caladium breeding. Similar knowledge gaps exist with somaclonal variants in many other ornamental plants and ornamental aroids.

To understand the cytological and/or molecular bases of somaclonal variation in caladium, Cao et al. (2016) screened regenerants from cultured leaf tissues of 'Red Flash' caladium, a cultivar known to be phenotypically stable during conventional tuber division-based propagation, identified somaclonal variants, and used cytological and molecular tools to study them. For the first time in caladium (and in aroids), they observed molecular marker banding pattern changes in these variants and showed that chromosome loss was a common genetic cause of somaclonal variation in 'Red Flash'. The question remaining to be answered was whether such kinds of chromosome number change and molecular marker banding pattern changes occur in other caladium cultivars.

In a prior study, Cai et al. (2015) applied in vitro mutation induction technique to caladium and treated cultured 'Tapestry' caladium leaf segments with colchicine. Cai et al. (2015) focused on identification and characterization of induced tetraploids, although a few plants with most obvious phenotypic changes were included in the analyses as well. Cai et al. (2015) demonstrated the effectiveness of colchicine treatments for doubling caladium chromosomes and induction of tetraploids. To answer the above-mentioned 
question, we re-screened 'Tapestry' caladium regenerants from Cai et al. (2015) and performed cytological and molecular marker analyses of those variants showing phenotypic changes and not having a doubled chromosome number (tetraploids) or nearly doubled chromosome numbers (tetraploid aneuploids). The objectives of this study were to (1) phenotypically evaluate these variants among regenerants of 'Tapestry' caladium treated with or without colchicine and (2) characterize these variants at the cytological (nuclear DNA content and chromosome number) and molecular (molecular marker banding pattern) level. New information was gained from characterizing these variants; it helped us gain a better understanding of caladium variants at the cellular and molecular levels and should facilitate wider adoption of these valuable sources of genetic variation in caladium breeding and breeding of other aroid plants.

\section{Materials and methods}

\section{Plant materials}

The commercial cultivar 'Tapestry' was used as the donor plant for tissue culture. This cultivar exhibits fancy-shaped leaves with large pink blotches, green leaf margins and red main veins (Deng et al. 2011). 'Tapestry' plants were forced from tubers and grown in plastic containers $(15 \mathrm{~cm}$ in diameter) filled with a commercial soilless potting mix (Fafard® 3B; Conrad Fafard, Inc., Agawam, MA, USA) supplemented with a controlled-release fertilizer (Osmocote®; The Scotts Company, Marysville, OH, USA) for $5 \mathrm{~g}$ per container. All pots were placed on metal benches and grown in a greenhouse under the natural photoperiod at the University of Florida's Gulf Coast Research and Education Center (UF/GCREC), Wimauma, FL, USA. Only immature leaves (about 2-week old) were collected from 'Tapestry' for tissue culture. First, those immature leaves were cleaned with faucet water for $30 \mathrm{~min}$, disinfected by $70 \%$ (v/v) alcohol for $15 \mathrm{~s}$ and treated with $0.5 \%(\mathrm{w} / \mathrm{v})$ sodium dichloroisocyanuric acid amended with Tween 20 (1-2 drops per $500 \mathrm{~mL}$ ) for $20 \mathrm{~min}$. After disinfection, the chemical remaining on leaves were removed by rinsing those leaves with autoclaved water for a total three times with each lasting for at least $15 \mathrm{~s}$.

\section{Leaf tissue culture and plant regeneration}

After removal of leaf margins, an autoclaved scalpel blade was used to trim leaf into small leaf segments $(\approx$ $0.5 \mathrm{~cm} \times 0.5 \mathrm{~cm})$. The operation was performed in a biological safety cabinet (Nuaire, MN, USA). The plant regeneration process followed somatic embryogenesis technique. First, the leaf segments were cultured in plastic Petri dishes
$(15 \times 100 \mathrm{~mm})$ filled with caladium callus induction medium 1 (CCI-1) containing $4.43 \mathrm{~g} \mathrm{~L}^{-1}$ commercial Murashige and Skoog (MS) (1962) medium (Product No. M519, PhytoTechnology Laboratories, KS, USA), $1 \mathrm{mg} \mathrm{L}^{-1} \mathrm{NAA}, 3 \mathrm{mg} \mathrm{L}^{-1}$ BA, 4\% (w/v) sucrose, and 0.8\% (w/v) agar (pH 5.8). All Petri dishes were incubated in a chamber with the ambient temperature controlled between 25 and $27^{\circ} \mathrm{C}$ and light intensity between 100 and $130 \mu \mathrm{mol} \mathrm{m}^{-2} \mathrm{~s}^{-1}$ for 4 weeks. Thereafter, various colchicine treatments were performed as described by Cai et al. (2015). Caladium cultures were immersed in the colchicine-containing liquid medium solution in glass jars wrapped with four to six layers of black cloth since colchicine is sensitive to light exposure. Those glass jars were then placed on a shaker with a low speed of $50 \mathrm{rpm}$. After treatment, the colchicine treated leaf cultures were washed using autoclaved water and then cultured on newly prepared CCI-1 medium to promote shoot regeneration for 2 months. Then, regenerated shoots were cultured on plantlet enhancement medium 2 (PE-2) for root induction.

\section{Plant acclimatization and establishment in the greenhouse}

After 5 months of tissue culture, regenerated plantlets were transferred from glass jars to 128 -cell planter trays $(2.5 \times 2.5 \times 2.5 \mathrm{~cm} /$ cell $)$ filled with a commercial soilless potting mix (Metro-mix ${ }^{\circledR}$; Sun Gro Horticulture, Agawam, MA, USA). All trays with plantlets were maintained in a growth chamber with temperatures controlled between 22 and $26{ }^{\circ} \mathrm{C}$, a constant light level of $150 \mu \mathrm{mol} \mathrm{m} \mathrm{m}^{-2} \mathrm{~s}^{-1}$ and a photoperiod of $16 \mathrm{~h}$ light and $8 \mathrm{~h}$ dark for 3 weeks. Then, plantlets were transferred to a greenhouse under natural photoperiod with temperatures controlled between 20 and $29^{\circ} \mathrm{C}$. All plants were misted twice per day and fed twice a week using a commercial liquid fertilizer containing $1.1 \%(\mathrm{w} / \mathrm{w})$ ammonia nitrogen, $11.8 \%(\mathrm{w} / \mathrm{w})$ nitrate nitrogen, $2.1 \%(\mathrm{w} / \mathrm{w})$ urea nitrogen, $5 \%(\mathrm{w} / \mathrm{w})$ phosphate $\left(\mathrm{P}_{2} \mathrm{O}_{5}\right)$, and $15 \%$ soluble potassium $\left(\mathrm{K}_{2} \mathrm{O}\right)$ (Peters ${ }^{\circledR}$ Excel, Everris, USA). Two months later, caladium plants were individually transferred from planter trays to plastic containers $(15 \mathrm{~cm}$ in diameter) filled with the soilless potting mix Fafard $3 B \circledR(C o n-$ rad Fafard, Inc.). Each plant in a container was fertilized with $5 \mathrm{~g}$ of a controlled-release fertilizer (Osmocote ${ }^{\circledR}$ ) and watered automatically through spaghetti tubes.

\section{Screening and morphological characterization of variants}

Previously, Cai et al. (2015) observed four diploid-like variants among these 'Tapestry' regenerants when they were investigating the efficiencies of various colchicine treatments for caladium tetraploidization and the corresponding 
morphological and cytological changes. Our further close observations suggested more diploid or diploid-like variants among these regenerants. Thus we aimed to conduct a more thorough examination and analysis of these caladium variants. To confirm potential new findings from new variants, we included, as control, the four variants (CK-26, C20D6-28, C10D4-113, and C10D4-17) that were previously characterized by Cai et al. (2015). We re-grew the four variants and all new variants side by side with the wildtype plants of 'Tapestry' in a greenhouse under the same conditions. All plants were forced from tubers. Colors of main veins, leaf blotches, and leaf margins were characterized using the Royal Horticultural Society (RHS) colour Chart (Royal Horticultural Society 1986). For each variant plant, multiple leaves were examined closely to ensure that the changes were stable and consistent, and then at least three fully expanded (mature), typical leaves per variant were used for data taking, morphological characterization, and description of morphological changes. For wildtype plants, three mature leaves from three individual plants were used for plant characterization. Only those regenerated plants showing distinct, stable morphological changes from wildtype were characterized as variants for further analysis.

\section{Nuclear DNA content determination}

The nuclear DNA content of variant plants and wildtype 'Tapestry' were determined using a Cyflow ${ }^{\circledR}$ Ploidy Analyser (Sysmex Europe GmbH, Norderstedt, Germany) and the protocol described by Doležel et al. (2007) and modified by Cao et al. (2014). Similar amount of leaf segments $(\approx 0.5 \times 0.5 \mathrm{~cm})$ from caladium and rye (Secale cereal) 'Daňkovské' were collected and co-chopped in $1 \mathrm{~mL}$ of cold LB01 lysis buffer in Petri dishes (Doležel et al. 2007). Rye plants were grown under the same condition and horticultural care with caladium plants. The nuclei suspension was filtered through a nylon mesh ( $50 \mu \mathrm{m}$ pore size) to remove plant debris. For each sample, $50 \mu \mathrm{L}$ of propidium iodide $\left(1 \mathrm{mg} \mathrm{mL}^{-1}\right)$ and RNase $\left(1 \mathrm{mg} \mathrm{mL}^{-1}\right)$ was added to nuclei suspension for staining nuclei and degrading RNA, respectively. After $5 \mathrm{~min}$ of incubation in dark, the prepared nuclei samples were fed into the flow cytometer for analysis. Three replicates (three leaves) were analyzed for each sample. The nuclear DNA content of variant plants were calculated as follows: 2C DNA content of sample $=$ nuclear DNA content of the internal reference ('Daňkovské', $16.19 \mathrm{pg} / 2 \mathrm{C}) \times$ (arithmetic mean of fluorescence value of caladium samples $\div$ arithmetic mean of fluorescence value of rye).

\section{Chromosome counting}

The growing root tips $(\approx 1 \mathrm{~cm}$ in length) containing meristem tissues were collected from wildtype 'Tapestry' and variant plants using surgical forceps. For pretreatment, those root tips were immersed in $0.002 \mathrm{M}$ 8-hydroxyquinoline solution for $3 \mathrm{~h}$ in dark at room temperature. Thereafter, root tips were fixed in a fixative solution containing three parts of methanol and one part of acetic acid at $4{ }^{\circ} \mathrm{C}$ for at least $4 \mathrm{~h}$. To soften root tissues, fixed root tips were rinsed under tap water for $1 \mathrm{~min}$ and then digested in $1 \mathrm{~N}$ hydrochloric acid $(\mathrm{HCl})$ at room temperature for $20-25 \mathrm{~min}$. The well hydrolyzed root tips (soft) were rinsed with deionized water for at least three times and then stained in the acetocarmine solution (Carolina Biology Supply Company, Burlington, NC, USA) for at least four hours. A sharp surgical scalpel was used to remove root caps and pick up the meristematic tissue onto a glass slide. The meristematic tissue was squashed under a cover glass. Slides were examined under a BH-2 microscope (Olympus, Tokyo, Japan). Slides having well-spread chromosomes were photographed under a BX-41 microscope (Olympus) using a Qlympus Q-color 5 camera and the Q-capture pro 7 software (QImaging, Surrey, Canada). For each variant, more than ten root tips were sampled for chromosome counting.

\section{SSR marker analysis}

Twenty 'Tapestry' variants (16 new and four previously reported by Cai et al. (2015), the wildtype 'Tapestry', 17 non-variant regenerated 'Tapestry' plants, and seven commercial caladium cultivars ('Red Flash', C103, 'Big Red', 'Dr. TL Meade', 'Blaze', 'Freida Hemple' and 'White Christimas') were analyzed with 22 caladium-specific SSR markers. The modified CTAB method described by Fulton et al. (1995) was used for extraction of total genomic DNA. DNA concentrations were estimated on a Nanodrop ${ }^{\mathrm{TM}} 1000$ spectrophotometer (Thermo Scientific, Odessa, TX, USA) and diluted to a working concentration of $8 \mathrm{ng} \mu \mathrm{L}^{-1}$. The simple sequence repeat (SSR) primers developed by Gong and Deng (2011) were used. Forward and reverse SSR primers were synthesized by Eurofins Scientific LLC (Huntsville, AL, USA) with an M13 tail (5'-CCCAGTCACGACGTTG-3') attached to each forward primer at the 5' end (Supplementary Table S1). Each PCR reaction contained $32 \mathrm{ng}$ of template genomic DNA, $2 \mathrm{mM}$ dNTPs, 0.25 unites of Taq DNA polymerase, $1 \times$ PCR reaction buffer, $1.5 \mathrm{mM} \mathrm{MgCl}{ }_{2}$ (New England Biolab, Ipswich, MA, USA), $2.0 \mathrm{pmol}$ of the reverse primer, 0.2 pmol of forward primer with an M13 tail, and $1.8 \mathrm{pmol}$ IRD700-labeled M13 tail primer (MWG, Highpoint, NC, USA). PCR amplification was conducted on a MasterCycler (Eppendorf, AG, Hamburg, Germany) thermal cycler following a touchdown program: denaturation at $94{ }^{\circ} \mathrm{C}$ for 2 min, seven cycles at $94{ }^{\circ} \mathrm{C}$ for $45 \mathrm{~s}, 68^{\circ} \mathrm{C}$ (decrease $2{ }^{\circ} \mathrm{C}$ progressively each cycle) for $45 \mathrm{~s}$, and $72^{\circ} \mathrm{C}$ for $60 \mathrm{~s}$, and then 30 cycles of $45 \mathrm{~s}$ at $94{ }^{\circ} \mathrm{C}, 45 \mathrm{~s}$ at $54{ }^{\circ} \mathrm{C}$ and $60 \mathrm{~s}$ for 
$72{ }^{\circ} \mathrm{C}$, and a final extension at $72{ }^{\circ} \mathrm{C}$ for $5 \mathrm{~min}$. The resultant PCR products were separated on $6.5 \%$ polyacrylamide gels and visualized on a LI-COR 4300 DNA analyser (LICOR, Lincoln, NE, USA). This experiment was independently repeated twice.

\section{Data analysis}

One-way analysis of variance (ANOVA) was conducted in the statistical software JMP 12.0 (SAS Institute Inc., Cary, NC, USA). The Dunnett's test $(P$ value $<0.05)$ was used for mean separation of the nuclear DNA contents between the wildtype and the variants. A hierarchical clustering analysis was also performed on the variants based on their SSR marker profiles in the same software using the "single" method; results from this analysis were displayed as a constellation plot.

Table 1 Summary of variants from leaf explants of 'Tapestry' caladium

\begin{tabular}{lccl}
\hline Treatment & $\begin{array}{l}\text { Plants established } \\
\text { in containers (no.) }\end{array}$ & Variants (no.) $)^{\mathrm{a}}$ & $\begin{array}{l}\text { Incidence } \\
\text { of variants } \\
(\%)^{\mathrm{b}}\end{array}$ \\
\hline Control (CK) & 60 & 7 & 11.67 \\
Colchicine & 441 & 13 & 2.94 \\
All & 501 & 20 & 3.99 \\
\hline
\end{tabular}

${ }^{\text {a }}$ Variants were identified on consistent morphological changes and confirmed over a period of at least 3 months

${ }^{\mathrm{b}}$ Incidence of variants $=$ number of variants observed divided by the total number plants examined $\times 100$

\section{Results}

\section{Identification of new variants}

Out of the 501 'Tapestry' plants regenerated by Cai et al. (2015), 68 exhibited phenotypic changes, and 48 had doubled or nearly doubled nuclear DNA contents. These regenerants were considered having changed to tetraploids (Cai et al. 2015) and were excluded from further analysis. The remaining 20 variants, including four that were first reported by Cai et al. (2015), had similar nuclear DNA contents with the wildtype (Table 1). Out of these, seven (35\%) were regenerated from leaf segments without colchicine treatment and $13(65 \%)$ were regenerated from leaf segments that were exposed to colchicine treatment. Thus, 16 new variants were discovered in this study.

\section{Morphological characterization of variants}

Based on leaf characteristics, these variants were separated into ten different variant types (VTs) (Table 2 and Fig. 1). CK-26 and C05D4-17 (reported by Cai et al. 2015) in VT1 were different from the wildtype and they displayed red leaf blotches and yellow green leaf margins. The leaves in VT2 (C05D6-11 and C05D4-36) differed from VT1 in the blotch and leave margin colors. Interestingly, red leaves were observed in VT3 (C20D6-28) (reported by Cai et al. 2015) which was distinctly different from other VTs. Plants of VT4 [C10D4-120, CK-27, C10D4-113 (reported by Cai et al. 2015), and C05D4-31] were very similar to the wildtype, except that their leaf lobes were closely attached and partially overlapped. Leaves in VT5 [C10D4-17 (reported by Cai et al. 2015), C10D2-23, and C10D4-3] were more

Table 2 Main leaf characteristics of wildtype 'Tapestry' and variant types regenerated from 'Tapestry'

\begin{tabular}{lllll}
\hline Variant type & Main veins $^{\mathrm{a}}$ & Leaf blotches $^{\mathrm{a}}$ & Leaf margins $^{\mathrm{a}}$ & Variant(s) \\
\hline Wildtype & Red (53B) & White (155C) & Green (137B) & Tapestry \\
VT1 & Red (53B) & Red (38A) & Yellow green (146B) & CK-26, C05D4-17 \\
VT2 & Red (53C) & Red (51A) & Green (137B) & C05D6-11, C05D4-36 \\
VT3 & Red (53B) & Red (36D) & Red (48A) & C20D6-28 \\
VT4 & Red (53B) & White (155C) & Green (137B) & C10D4-120, CK-27, C10D4-113, C05D4-31 \\
VT5 & Red (53B) & White (155C) & Green (137B) & C10D4-17, C10D2-23, C10D4-3 \\
VT6 & Red (54B) & Green white (157C) & Green (131A) & CK-46 \\
VT7 & Red (54A) & No blotches & Green (137B) & C05D4-13 \\
VT8 & Red (48B) & No blotches & Green (137B) & CK-10, CK-53, C05D2-66 \\
VT9 & Green (137B) & White (155C) & Green (137B) & C05D2-34, CK-22 \\
VT10 & Red (54A) & White (155C) & Green (137B) & CK-47 \\
\hline
\end{tabular}

${ }^{a}$ Color of main veins, leaf blotches and leaf margins were visually determined by comparing to the Royal Horticultural Society (RHS 1986) Colour Chart. Number and letters in parenthesis show the closest match of color shade in the RHS Colour Chart. All sampled caladium plants were grown in containers in a greenhouse 


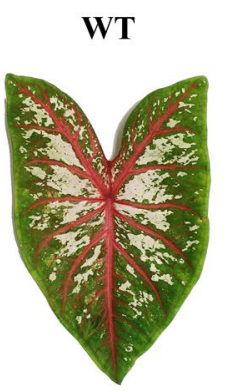

VT6

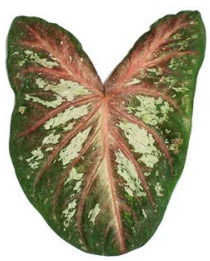

VT1

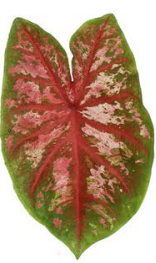

VT7

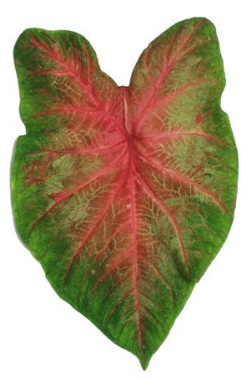

VT2

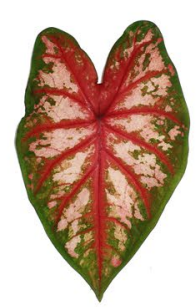

VT3



VT8

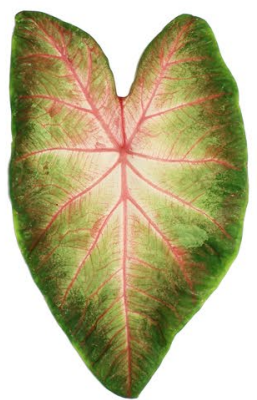

VT5

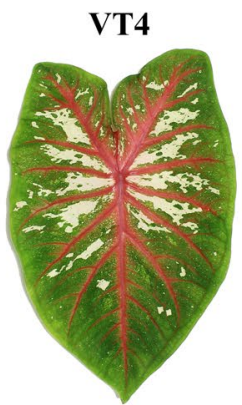

VT9

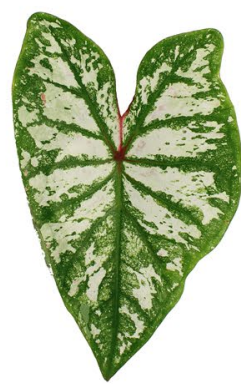

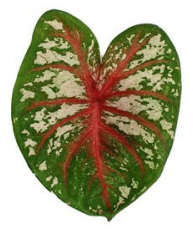

VT10

Fig. 1 Representative leaves of the wildtype (WT) 'Tapestry' caladium and ten variant types (VT). Scale bar $=3 \mathrm{~cm}$

rounded. Unlike the wildtype, the plant in VT6 (CK-46) had pale red main veins, white blotches, and light green leaf margins. Variants in both VT7 (C05D4-13) and VT8 (CK10, CK-53, and C05D6-11) lost blotches on leaves, and the former had pale red main veins and yellow green interveinal areas, and the latter possessed venetian red main veins and red interveinal areas. Among all VTs and the wild type, only plants in VT9 (C05D2-34 and CK-22) showed vein color changes (red to green). In addition, we also observed one variant possessing chimeric leaves consisting of wildtypeand VT7-like leaf areas. This variant was therefore grouped into VT10.

\section{Nuclear DNA contents}

Wildtype 'Tapestry' had a nuclear DNA content of $9.16 \mathrm{pg} / 2 \mathrm{C}$ (Table 3). The nuclear DNA content of CK-26 (reported by Cai et al. 2015) and C05D4-17 in VT1, C20D628 (reported by Cai et al. 2015) in VT3, CK-27 and C04D431 in VT4, C10D4-17 (reported by Cai et al. 2015), C10D223 and C10D4-3 in VT5, CK-10 in VT8, C05D2-34 in VT9, and CK-47 in VT10 ranged from 9.01 to $9.23 \mathrm{pg} / 2 \mathrm{C}$, approximately $98.8 \%$ to $100.8 \%$ of the wildtype's DNA content.

Other variants showed significant increases or decreases in their nuclear DNA contents compared with the wildtype. C05D6-11 and C05D4-36 (in VT2) had 5.3-5.5\% higher nuclear DNA content than the wildtype. In VT4, C10D4-120 had $4.2 \%$ lower DNA content than the wildtype, whereas C10D4-113 (reported by Cai et al. 2015) had 9.7\% higher
DNA content. In VT6, CK-46 had 3.0\% lower nuclear DNA content, contrasting to C05D4-13 in VT7, which had 5.8\% higher DNA content than the wildtype. In VT8, CK-53 and C05D2-66 contained 4.5-4.8\% lower nuclear DNA than the wildtype. In VT9, CK-22 had 3.3\% higher nuclear DNA content than the wildtype.

Overall, the nuclear DNA contents in these variants ranged from 8.74 (in CK-53) to $10.14 \mathrm{pg} / 2 \mathrm{C}$ (in C10D4113 ), which is $4.8 \%$ lower to $9.7 \%$ higher than the nuclear DNA content of the wildtype. Eleven variants (CK-26, C05D4-17, C20D6-28, CK-27, C04D40-31, C10D4-17, C10D2-23, C10D4-3, CK-10, C05D2-34, and CK-47) and the wildtype had similar nuclear DNA contents, while five variants (C05D6-11, C05D4-36, C10D4-113, C05D4-13, and CK-22) contained 3.3-9.7\% more nuclear DNA than the wildtype, and four variants (C10D4-120, CK-46, CK-53, and C05D2-66) had 3.0-4.8\% less nuclear DNA than the wildtype.

\section{Chromosome counting}

A total of 174 metaphases from 20 variants and the wildtype had well-spread chromosomes and they were carefully examined for chromosome numbers. The wildtype 'Tapestry' had $2 x=30$ chromosomes, consistent with the previous studies (Cao et al. 2014; Cai et al. 2015) (Table 3; Fig. 2b). Eleven variants [CK-26 (reported by Cai et al. 2015) and C05D4-17 in VT1, C20D6-28 (reported by Cai et al. 2015) in VT3, CK-27 and C05D4-31 in VT4, 
Table 3 Nuclear DNA content, chromosome number and SSR banding patterns of wildtype 'Tapestry' caladium and 20 variants regenerated from 'Tapestry'

\begin{tabular}{|c|c|c|c|c|c|c|c|c|c|c|c|}
\hline \multirow[t]{2}{*}{ Variant } & \multirow{2}{*}{$\begin{array}{l}\text { Variant } \\
\text { type } \\
\text { (VT) }\end{array}$} & \multirow{2}{*}{$\begin{array}{l}\text { Nuclear } \\
\text { DNA content } \\
\pm \text { standard } \\
\text { deviation } \\
(\mathrm{pg} / 2 n)\end{array}$} & \multirow{2}{*}{$\begin{array}{l}\text { Nuclear } \\
\text { DNA } \\
\text { change } \\
\text { compared } \\
\text { to wildtype } \\
(\%)\end{array}$} & \multirow{2}{*}{$\begin{array}{l}\text { Metaphases } \\
\text { observed } \\
\text { (no.) }\end{array}$} & \multirow{2}{*}{$\begin{array}{l}\text { Chromosome } \\
\text { number } \\
\text { observed }\end{array}$} & \multicolumn{6}{|c|}{ SSR marker profiling } \\
\hline & & & & & & CaM18 & CaM24 & CaM42 & CaM48 & CaM62 & $\begin{array}{l}\text { SSR } \\
\text { banding } \\
\text { pattern } \\
\text { changes }\end{array}$ \\
\hline Tapestry & Wildtype & $9.16 \pm 0.10$ & 0 & 13 & $2 x=30$ & ++ & ++ & ++ & ++ & ++ & No \\
\hline CK-26 & 1 & $9.12 \pm 0.03^{\mathrm{ns}}$ & -0.4 & 7 & $2 x=30$ & ++ & ++ & ++ & + & ++ & Yes \\
\hline C05D4-17 & 1 & $9.09 \pm 0.05^{\mathrm{ns}}$ & -0.8 & 6 & $2 x=30$ & ++ & ++ & ++ & ++ & ++ & No \\
\hline C05D6-11 & 2 & $9.69 \pm 0.13^{*}$ & +5.5 & 9 & $2 x+3=33$ & ++ & ++ & ++ & ++ & ++ & Yes \\
\hline C05D4-36 & 2 & $9.67 \pm 0.15^{*}$ & +5.3 & 6 & $2 x+2=32$ & ++ & + & ++ & ++ & + & Yes \\
\hline C20D6-28 & 3 & $9.18 \pm 0.03^{\mathrm{ns}}$ & +0.2 & 5 & $2 x=30$ & ++ & ++ & ++ & ++ & ++ & No \\
\hline C10D4-120 & 4 & $8.79 \pm 0.03^{*}$ & -4.2 & 10 & $2 x-1=29$ & ++ & + & ++ & ++ & + & Yes \\
\hline CK-27 & 4 & $9.03 \pm 0.05^{\mathrm{ns}}$ & -1.4 & 6 & $2 x=30$ & ++ & + & ++ & ++ & + & Yes \\
\hline C10D4-113 & 4 & $10.14 \pm 0.19^{*}$ & +9.7 & 12 & $2 x+1=31$ & ++ & ++ & ++ & ++ & ++ & No \\
\hline C05D4-31 & 4 & $9.12 \pm 0.02^{\mathrm{ns}}$ & -0.4 & 11 & $2 x=30$ & ++ & ++ & ++ & ++ & ++ & No \\
\hline C10D4-17 & 5 & $9.08 \pm 0.08^{\mathrm{ns}}$ & -0.9 & 9 & $2 x=30$ & ++ & ++ & ++ & ++ & ++ & No \\
\hline C10D2-23 & 5 & $9.22 \pm 0.54^{\mathrm{ns}}$ & +0.7 & 10 & $2 x=30$ & + & ++ & ++ & ++ & ++ & Yes \\
\hline C10D4-3 & 5 & $9.23 \pm 0.11^{\mathrm{ns}}$ & +0.8 & 9 & $2 x=30$ & ++ & ++ & ++ & ++ & ++ & No \\
\hline CK-46 & 6 & $8.89 \pm 0.15^{*}$ & -3.0 & 7 & $2 x-1=29$ & ++ & + & ++ & ++ & + & Yes \\
\hline C05D4-13 & 7 & $9.72 \pm 0.12^{*}$ & +5.8 & 7 & $2 x+1=31$ & ++ & ++ & + & ++ & ++ & Yes \\
\hline CK-10 & 8 & $9.01 \pm 0.11^{\mathrm{ns}}$ & -1.7 & 5 & $2 x=30$ & ++ & ++ & + & ++ & ++ & Yes \\
\hline CK-53 & 8 & $8.74 \pm 0.03^{*}$ & -4.8 & 11 & $2 x-1=29$ & ++ & ++ & + & ++ & ++ & Yes \\
\hline C05D2-66 & 8 & $8.77 \pm 0.04^{*}$ & -4.5 & 6 & $2 x-1=29$ & ++ & ++ & + & ++ & ++ & Yes \\
\hline $\mathrm{C} 05 \mathrm{D} 2-34$ & 9 & $9.13 \pm 0.26^{\mathrm{ns}}$ & -0.3 & 11 & $2 x=30$ & ++ & ++ & + & ++ & ++ & Yes \\
\hline CK-22 & 9 & $9.47 \pm 0.11^{*}$ & +3.3 & 9 & $2 x+1=31$ & ++ & ++ & + & ++ & ++ & Yes \\
\hline CK-47 & 10 & $9.14 \pm 0.11^{\mathrm{ns}}$ & -0.2 & 5 & $2 x=30$ & ++ & ++ & ++ & ++ & ++ & No \\
\hline Total & 21 & 8.74 to 10.14 & $\begin{array}{l}-4.8 \text { to } \\
+9.7\end{array}$ & 174 & $\begin{array}{l}2 x-1=29 \text { in } \\
\text { four variants, } \\
2 x=30 \text { in } 11 \\
\text { variants and } \\
\text { the wildtype, } \\
2 x+1=31 \text { in } \\
\text { three variants, } \\
2 x+2=32 \text { in } \\
\text { two variants, } \\
2 x+3=33 \text { in } \\
\text { one variant. }\end{array}$ & $\begin{array}{l}\text { Band } \\
\text { missing } \\
\text { in one } \\
\text { variant }\end{array}$ & $\begin{array}{l}\text { Band } \\
\text { missing } \\
\text { in four } \\
\text { variants } \\
; \\
\text { Band } \\
\text { shifting } \\
\text { in one } \\
\text { variant }\end{array}$ & $\begin{array}{l}\text { Band } \\
\text { missing } \\
\text { in six } \\
\text { variants }\end{array}$ & $\begin{array}{l}\text { Band } \\
\text { missing } \\
\text { in one } \\
\text { variant }\end{array}$ & $\begin{array}{l}\text { Band } \\
\text { missing } \\
\text { in four } \\
\text { variants }\end{array}$ & $\begin{array}{l}65 \% \\
(13 / 20) \\
\text { variants } \\
\text { showed } \\
\text { SSR band } \\
\text { changes for } \\
\text { five SSR } \\
\text { markers }\end{array}$ \\
\hline
\end{tabular}

Nuclear DNA contents of the wildtype 'Tapestry' caladium and variants were determined using a Cyflow® Ploidy Analyser and the rye (Secale cereal) cultivar 'Daňkovské' as the internal reference (Doležel et al. 2007). Mean separation between the wildtype and variants in nuclear DNA content was performed according to the Dunnett's test $(P<0.05)$. ns no significant difference between the variant and the wildtype in nuclear DNA content, and asterisk: significant difference between the variant and the wildtype in nuclear DNA content. The percentage changes of nuclear DNA contents were calculated using a formula: (nuclear DNA content of the variant - nuclear DNA content of the wildtype) $\div$ nuclear DNA content of the wildtype $\times 100$. Chromosome numbers were determined by squashing root tip cells and staining them with aceto-carmine. The banding patterns of SSR markers were shown by plus symbols; each plus symbol represents one SSR band; and front symbols represents DNA bands of larger molecular weights or more base pairs (upper bands on the gel) while rear symbols represents DNA bands of smaller molecular weights or fewer base pairs (lower bands on a gel)

C10D4-17 (reported by Cai et al. 2015), C10D2-23, and C10D4-3 in VT5, CK-10 in VT8, C05D2-34 in VT9, and CK-47 in VT10] also had $2 n=2 x=30$ chromosomes. Four variants C10D4-120 in VT4, CK-46 in VT6, and CK-53 and
C05D2-66 in VT8) that had less nuclear DNA (3.0-4.8\% lower) lost one chromosome $(2 n=2 x-1=29$, monosomics) (Fig. 2a). Three variants [C10D4-113 (reported by Cai et al. 2015) in VT4, C05D4-13 in VT7, and CK-22 in VT9)] with 




Fig. 2 Micrographs $(\times 1000)$ of chromosomes in the root tips of the wildtype caladium and five variants C05D2-66, C05D4-13, C05D436, C05D6-11, and C10D4-113. a C05D2-66 $(2 n=2 x=29)$, b wildtype $(2 n=2 x=30)$, c C05D4-13 $(2 n=2 x+1=31)$, d CK-22 $(2 n=2 x+1=31)$, e C05D4-36 $(2 n=32)$, and f C05D6-11 $(2 n=33)$. Scale bar $=10 \mu \mathrm{m}$ increased nuclear DNA contents $(3.3-9.7 \%$ higher) gained one extra chromosome $(2 n=2 x+1=31$, trisomics) (Fig. $2 \mathrm{c}$ and d). Two variants in VT2 (C05D6-11 and C05D4-36) with increased nuclear DNA contents (5.3-5.5\% higher) gained two (C05D4-36) or three chromosomes (C05D6-11) (Fig. 2e, f).

\section{SSR marker analysis}

All markers produced one or two clear DNA bands on $6.5 \%$ polyacrylamide gels (Fig. 3). Seven commercial cultivars ('Big Red', 'Blaze', C103, 'Dr. TL Meade', 'Freida Hemple', 'Red Flash' and 'White Christmas') were included in the analysis because they shared similar main vein colors and/ or leaf coloration patterns with some of the 20 variants/ mutants. These cultivars showed distinct banding patterns from any of the variants/mutants with markers CaM18, CaM42 and CaM48 (Fig. 3a, c, d). All 17 non-variants showed the same banding pattern as the wildtype 'Tapestry'.

Of the 20 SSR markers, five (CaM18, CaM24, CaM42, CaM48, and CaM62) detected banding pattern changes in the 'Tapestry' variants (Table 3; Fig. 3). C10D20-23 lost one of the two bands (upper or "larger") amplified by the marker CaM18 (Fig. 3a). CK-27 lost the lower band ("smaller" amplicon or allele) amplified by CaM24, while CK-46, C05D4-36, and C10D4-120 lost the upper band ("larger" amplicon or allele) amplified by marker CaM24 (Fig. 3b). Interestingly, C05D6-11 showed a new allele with marker CaM24 (Fig. 3b). Marker CaM42 revealed DNA banding changes in six variants: CK-10, CK-53, C05D2-66 and C05D4-13 lost the lower band, while CK-22 and C05D234 lost the upper band (Fig. 3c). Marker CaM48 detected a band loss in CK-26 (Fig. 3d). Marker CaM62 detected loss of an upper band in CK-27 and loss of a lower band in CK46, C05D4-36, and C10D4-120 (Fig. 3e). Interestingly, CK-27, CK-46, C05D4-36 and C10D4-120 showed banding pattern changes with both markers CaM24 (Fig. 3b) and CaM62 (Fig. 3e).

Based on the profiles of these SSR markers, a hierarchical analysis was performed on these variants. In this analysis and as displayed as a constellation plot, these variants fell into four clusters, with C05D4-13, CK-10, CK-53, C05D266, C05D2-34, and CK-22 in cluster 1, C10D2-23, C05D611, CK-26, CK-47, C10D4-3, C10D4-17, C05D4-31, C10D4-113, C20D6-28 and C05D4-17 in cluster 2, C05D436, C10D4-120, and CK-46 in cluster 3, and CK-27 in cluster 4 (Fig. 4). The six variants in cluster 1 each lost one band (upper or lower) amplified by marker CaM42. Cluster 
2 consists of 10 variants, among which six didn't show significant changes in nuclear DNA content, chromosome number or SSR banding pattern, one (C10D4-113) contained 9.7\% more nuclear DNA and one additional chromosome, two (CK-26 and C10D2-23) showed a SSR banding pattern change with marker CaM18 or CaM48, and one (C05D6-11) had three additional chromosomes and a SSR banding pattern change. Thus this cluster consists of diverse variants. The three variants (C05D4-36, C10D4-120, and CK-46) in cluster 3 shared the same SSR marker banding pattern change: Loss of the upper band amplified by marker CaM42 and the lower band of marker CaM62. Cluster 4 contains only one variant, CK-27, which showed SSR marker banding pattern changes with two markers (CaM24 and CaM62).

\section{Discussion}

As a mitotic inhibitor, colchicine has been widely used to induce chromosome doubling. However, some studies also indicated that it could induce other types of mutations (Datta 2014; Manzoor et al. 2019; Van Harten 1998). For this reason, we could designate those variants from 'Tapestry' leaf segment cultures treated with colchicine as induced mutants. However, as shown below, it remains to be determined whether or not those variants from colchicine-treated cultures were induced by colchicine, so we chose to use "variants" to refer to all regenerants that showed consistent changes from the wildtype plants, no matter whether they were from colchicine-treated or non-treated leaf cultures.

Sixteen new variants were identified out of 501 regenerated 'Tapestry' caladium plants. When the four variants previously reported by Cai et al. (2015) were taken into account, a total of 13 variants were identified out of 441 regenerants from cultures exposed to colchicine treatments, and seven variants were observed among 60 regenerants from cultures not exposed to any colchicine treatments (the control group). Thus, the frequency of variants in the colchicine-treated and the non-treated cultures was $2.9 \%$ and $11.7 \%$, respectively (Table 1 ). These results seem to suggest that the colchicine treatments didn't increase the occurrence of variants in this study. To answer the question whether or not colchicine will induce genetic mutations beyond chromosome doubling in caladium, it may require the use of different types of explants/cultures and/or culturing conditions that give rise to much less somaclonal variation and won't mask any potential mutagenic effects of colchicine. Ahmed et al. $(2002,2004)$ showed that young explants and low concentrations of auxin in the medium could reduce the incidences of somaclonal variation. These conditions should be used in future experiments aiming to determine the potential mutagenic effects of colchicine in caladium.
The variants identified in this study can be a very valuable source of novel or improved foliar characteristics for caladium breeding. Due to the intensive selection for generations, the restricted genetic variability in the caladium breeding germplasm significantly bottlenecks the development of new caladium phenotypes, even in large breeding populations (Deng 2012). In this study, we observed several caladium variants displaying novel foliar phenotypes. Among them, C20D6-28 (VT3) had full red leaves, which significantly differs from the wildtype, other variants and the existing commercial cultivars. C05D6-11 and C05D4-36 (VT2) display unique pink blotches, which is a very interesting phenotype warranting the further development. As caladium can be readily propagated by asexual tuber division, these variants could be propagated to serve as breeding lines for further field assessment or as parental lines for introgressing those novel traits to commercial cultivars.

Among nine variants (C05D6-11, C05D4-36, C10D4120, C10D4-113, CK-46, C05D4-13, CK-53, C05D2-66 and CK-22) which were determined as aneuploids $(2 n=29,31$, 32 , or 33), four variants (C10D4-120, CK-46, CK-53, and C05D2-66) lost one chromosome, and they might be called monosomics $(2 n=2 x-1$, as shown in Table 3$)$, although it remains to be determined that which of the 30 chromosomes was lost in these variant. Similarly, three of the variants (C10D4-113, C05D4-13, and CK22) that gained one chromosome might be tentatively designated as trisomics $(2 n=2 x+1$, Table 3). C05D4-36 and C05D6-11 gained two or three chromosomes and they were tentatively referred to as $2 n=2 x+2$ (tetrasomic) and $2 n=2 x+3$ (pentasomic), respectively, in Table 3 . It should be pointed out that this referring was for simplicity and the designation was premature, because it was difficult to determine whether or not the gained two or three chromosomes were from one, two, or three specific pairs of 'Tapestry's chromosomes. Additional research is needed to determine if C05D4-36 should be referred to as $2 n=2 x+2$ or $2 x+1+1$, and C05D6-11 as $2 x+3,2 x+2+1$, or $2 x+1+1+1$.

The above results indicated that determination of nuclear DNA contents could be used for initial screen of variants prior to chromosome squashing and counting, which are more time-consuming and tricky. Four variants (C10D4120, CK-46, CK-53 and C05D2-66) lost one chromosome, and their nuclear DNA contents were reduced by $3.0-4.8 \%$ compared to the DNA content of the wildtype 'Tapestry'. These nuclear DNA content reductions were close to the expected average proportion of one "average" chromosome in 'Tapestry' caladium genome ( 1 divided by 30 chromosomes $=3.3 \%$ of the entire genome). Previous studies (Cao et al. 2016; Cao and Deng 2016) reported that monosomics somaclonal variants of the caladium cultivar 'Red Flash' that lost 2.3-5.6\% nuclear DNA lost Chromosome 2. This chromosome appeared to be instable in caladium and prone 


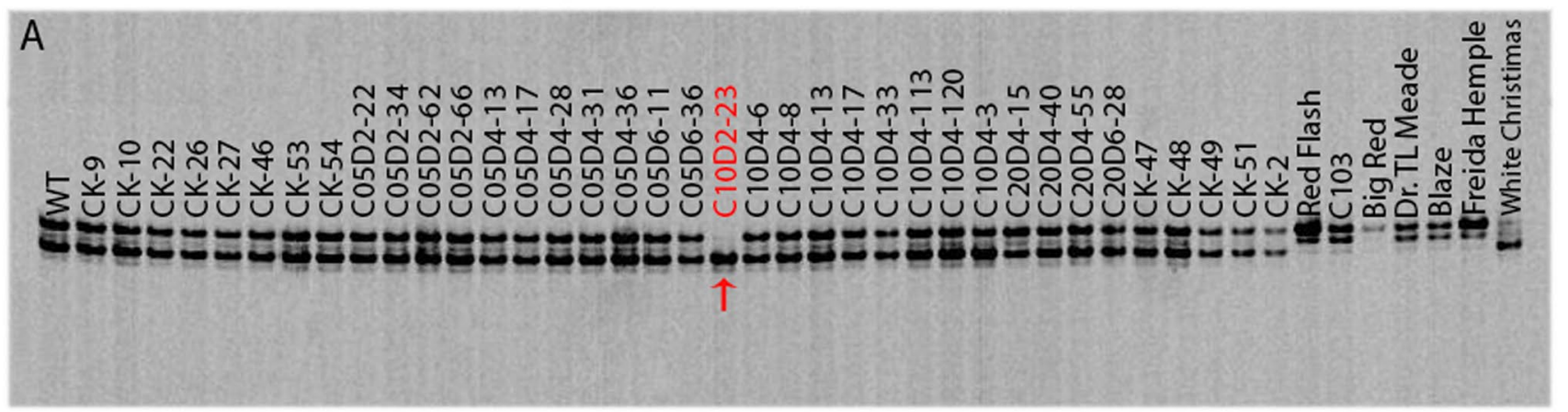

B

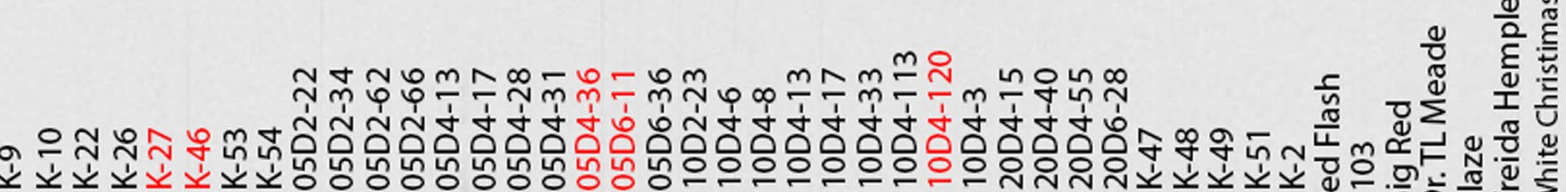


a 2 a $\uparrow \uparrow \uparrow \uparrow \uparrow \uparrow$

C



D

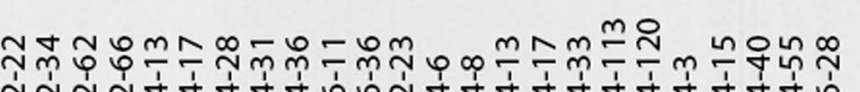

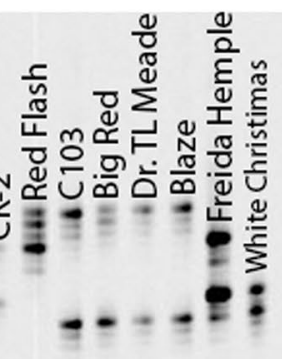

E

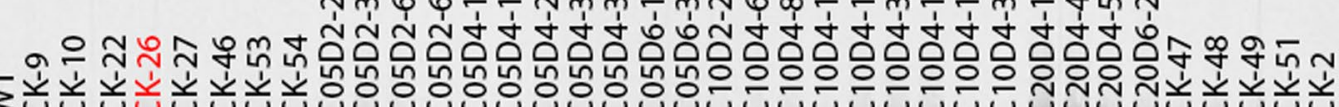



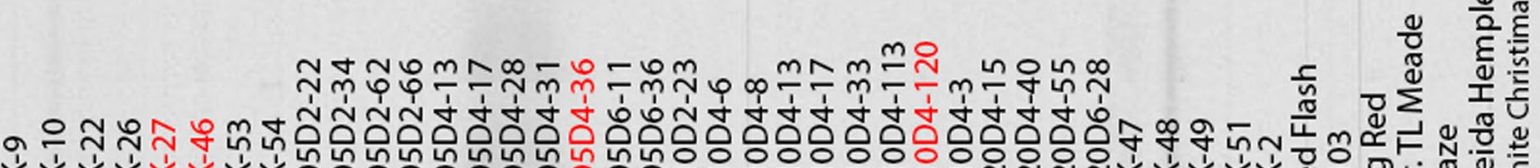

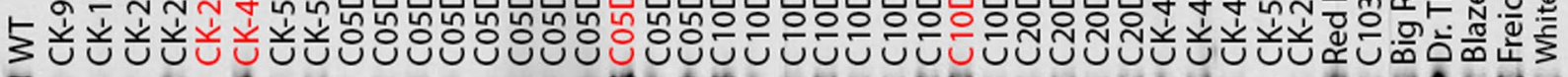

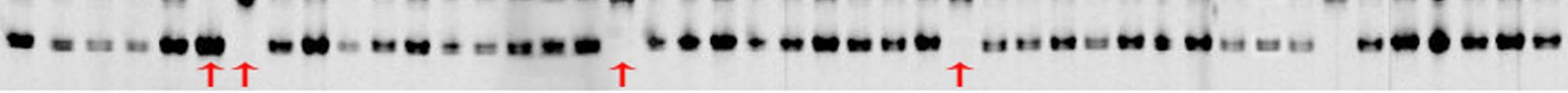

to loss (Cao et al. 2016). It is likely that monosomic 'Tapestry' caladium variants C10D4-120, CK-46, CK-53 and/or C05D2-66 might have lost Chromosome 2 also.

The nuclear DNA contents of three putative trisomics (C10D4-113, C05D4-13, and CK-22) ranged from 9.47 to
$10.14 \mathrm{pg} / 2 \mathrm{C}$. Theoretically, if these variants gained one more copy of the same chromosome, they should have similar nuclear DNA contents. Our results seem to point that these variants each might have gained an extra copy of different chromosomes. C10D4-113 might have gained one copy of 
4Fig. 3 SSR banding pattern of the wildtype (WT) 'Tapestry' caladium, seven commercial caladium cultivars ('Red Flash', C103, 'Big Red', 'Dr. TL Meade', 'Blaze', 'Freida Hemple', and 'White Christmas'), 20 'Tapestry' variants (CK-10, CK-22, CK-26, CK-27, CK-46, CK-47, CK-53, C05D2-34, C05D2-66, C05D4-13, C05D4-17, C05D4-31, C05D4-36, C05D6-11, C10D2-23, C10D4-113, C10D4120, C10D4-17, C10D4-3, and C20D6-28), and 17 normal-looking regenerated 'Tapestry' plants (CK-2, CK-9, CK47, CK48, CK-49, CK-51, CK-54, C05D2-22, C05D2-62, C05D4-28, C10D4-6, C10D48, C10D4-13, C10D4-33, C20D4-15, C20D4-40, and C20D4-55). a Banding patterns of SSR marker CaM18. b Banding patterns of SSR marker CaM24. c Banding patterns of SSR marker CaM42. d Banding patterns of SSR marker CaM48. e Banding patterns of SSR marker CaM62. Red arrows point to the modified SSR bands in regenerated variants. (Color figure online)

a larger or longer chromosome, while C05D4-13 and CK-22 might have gained a smaller or shorter chromosome.

Five SSR markers detected loss of DNA bands (or alleles) in 12 variants and a new DNA band (or allele) in one variant. The SSR band loss or band size change could be due to nucleotide sequence changes (substitutions, insertions, deletions, and/or inversions) at the corresponding SSR primer-binding sites or amplified region between two primers. Interestingly, CaM24 and CaM62 detected the same SSR banding pattern changes in four out of five variants (C05D4-36, C10D4-120 and CK-46 in cluster 3, and CK-27 in cluster 4 ), which equals to a correlation coefficient of 0.8 (4 out 5 variants) between two markers. The high correlation $(r=0.8)$ of banding pattern changes in the five variants between CaM24 and CaM62 seems to indicate that these two markers are close to each other in the same chromosomal segment and the chromosomal segment carrying these markers were instable during tissue culture. As physical interactions among chromosomes have been frequently reported (Maas et al. 2018), it is also possible that these two markers located in different chromosomes but within the interaction site which might be disrupted under in vitro environment.

In cluster 1, four variants (C05D4-13, CK-10, CK-53, and C05D2-66) losing the "smaller" allele at the CaM42 marker locus also lost leaf blotches, a typical coloration pattern of wildtype 'Tapestry', and the two variants (CK-22 and C05D2-34) that lost the "bigger" allele at the CaM42 marker locus had their main vein color changed from red to green. Previously, Deng and Harbaugh $(2006,2009)$ reported that leaf blotching in caladium is controlled by a single nuclear locus $(B)$, with the leaf blotching allele $(B)$ dominant over the non-blotching allele $(b)$ and the leaf main vein color in caladium is controlled by another single nuclear locus $(V)$, with the red allele $\left(V^{n}\right)>$ white allele $\left(V^{\mathrm{w}}\right)>$ green allele $\left(V^{\mathrm{g}}\right)$. Deng and Harbaugh (2009) also demonstrated that the $B$ and the $V$ locus in caladium are closely linked. The genotype of 'Tapestry' at these two loci is $B V^{\mathrm{g}} / / / b V^{\mathrm{r}}$ (Cao and Deng, unpublished), based on phenotyping a large number of progeny from the crosses between 'Tapestry' [blotched
$(B b)$ and red-veined $\left.\left(V^{g} V^{r}\right)\right]$ and other cultivars or breeding lines [non-blotched $(b b)$ and green-veined $\left(V^{g} V^{g}\right)$ ] and finding that the majority of progeny were blotched and greenveined or non-blotched and red-veined and that the allele $B$ is in coupling phase with $V^{\mathrm{g}}$, and $b$ is in coupling phase with $V^{\mathrm{r}}$. These previous studies suggest that if the chromosomal segment containing the blotching allele $(B)$ and the green vein allele $\left(V^{g}\right)$ is lost, the resultant 'Tapestry' variants should be non-blotched and red-veined (Type 1 variant phenotype), and if the chromosomal fragment carrying the nonblotching allele $(b)$ and the red vein allele $\left(V^{r}\right)$ is lost, the resultant 'Tapestry' variants should be blotched and green veined (Type 2 variant phenotype). Variant C05D2-34 and CK-22 had the Type 2 phenotype (blotches and green veins) and both lost the "bigger" allele of marker CaM42, while four variants (C05D4-13, C05D2-66, CK-10, and CK-53) had the Type 1 variant phenotype (no blotches and red veins) and they all lost the "smaller" allele of CaM42. The strong association among the leaf blotching and leaf vein color phenotype and the alleles of CaM42 seem to suggest that marker CaM42 be linked with the $B$ locus and the $V$ locus, and further suggest that the "bigger" allele of CaM42 be in a coupling phase with the leaf blotching allele $(B)$ and the green vein allele $\left(V^{g}\right)$ and the "smaller" allele of CaM42 be in a coupling phase with the non-blotching allele $(b)$ and the red veined allele $\left(V^{r}\right)$. These inferences about the association or linkage between molecular markers and morphological traits are very valuable. Future trait and marker segregation data from controlled crosses and biparental populations can be used to validate such association. These results clearly show potential uses of variants in a range of research toward understanding the genetic bases of variation in plants and associating molecular markers with important traits in horticultural or agronomic crops.

This study identified 16 new variants among the 'Tapestry' caladium regenerants that were first reported by Cai et al. (2015). Detailed cytological and molecular marker analyses in this study revealed a considerable amount of new information about caladium variants. Twenty-five percent of the 'Tapestry' variants gained one to three chromosomes and $20 \%$ of the variants lost one chromosome (Table 3), indicating that in addition to chromosome loss, chromosome gain is also a common genetic cause of variation in caladium. This complements a previous finding by Cao et al. (2016) where only chromosome loss was observed. Recently, Zhang et al. (2020) also observed chromosome gain in 'Red Flash' caladium variants, confirming that chromosome gain may be more common than previously thought. SSR marker analysis was first applied by Cao et al. (2016) to caladium variants; the authors showed that two caladium-specific SSR markers (CaM1 and CaM103) changed banding patterns in those caladium variants. This study detected marker banding 
Fig. 4 Hierarchical clustering analysis of 20 variants based on profiles of SSR markers. Constellation plot was used for result visualization. Each dot represents a variant. Variants possessing the same color belong to the same cluster. (Color figure online)

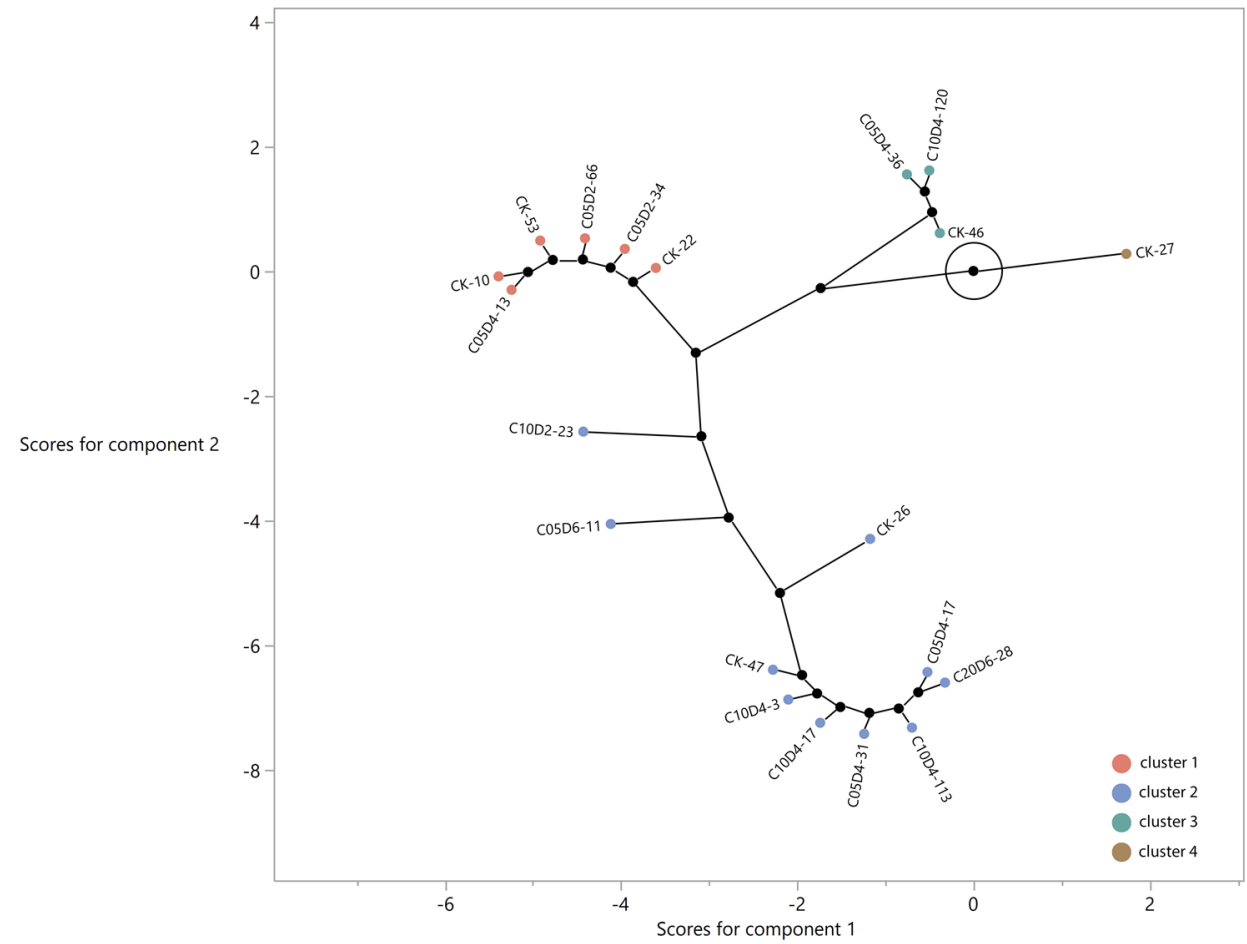

pattern changes with five different SSR markers (CaM18, CaM24, CaM42, CaM48, and CaM62), and as much as $65 \%$ of variants exhibited banding pattern changes with one or two of these SSR markers. Thus, these findings at the cellular and molecular levels suggest diverse genetic changes in these 'Tapestry' variants.

In conclusion, the detailed characterization of 'Tapestry' caladium variants indicates that they have genetic bases at both the molecular and cellular levels. The identified variants can provide a valuable source of novel traits for caladium breeding and/or can be used as a new tool for better understanding of the inheritance of important traits and establishing trait-marker association.

Acknowledgements We thank Dr. Shixiao Xu for culturing caladium leaf segments and producing caladium plantlets, and Dr. Xiaodong Cai for transplanting and caring caladium plants in the greenhouse. We are grateful to Dr. Samuel Hutton for giving us access to the Nanodrop spectrophotometer and Dr. Jaroslav Doležel (Institute Experimental Botany, Olomouc, Czeck Republic) for providing rye seeds. This project was funded in part by the USDA/NIFA hatch projects (Project \# FLA-GCR-005065 and FLA-GCC-005507).

Author contributions $\mathrm{ZC}$ conducted this research, analyzed the results, and drafted the manuscript. ZD designed and supervised the experiments and revised and finalized the manuscript.

\section{Compliance with ethical standards}

Conflict of interest The authors declare no conflict of interests.
Open Access This article is licensed under a Creative Commons Attribution 4.0 International License, which permits use, sharing, adaptation, distribution and reproduction in any medium or format, as long as you give appropriate credit to the original author(s) and the source, provide a link to the Creative Commons licence, and indicate if changes were made. The images or other third party material in this article are included in the article's Creative Commons licence, unless indicated otherwise in a credit line to the material. If material is not included in the article's Creative Commons licence and your intended use is not permitted by statutory regulation or exceeds the permitted use, you will need to obtain permission directly from the copyright holder. To view a copy of this licence, visit http://creativecommons.org/licenses/by/4.0/.

\section{References}

Ahmed E, Hayashi T, Yazawa S (2004) Auxins increase the occurrence of leaf-color variants in caladium regenerated from leaf explants. Sci Hortic 100:153-159

Ahmed E, Hayashi T, Zhu Y, Hosokawa M, Yazawa S (2002) Lower incidence of variants in Caladium bicolor Ait. plants propagated by culture of explants from younger tissue. Sci Hortic 96:187-194

Cai X, Cao Z, Xu S, Deng Z (2015) Induction, regeneration and characterization of tetraploids and variants in 'Tapestry' caladium. Plant Cell Tissue Organ Cult 120:689-700

Cao Z, Deng Z (2016) Karyotypic variation among somaclonal variants of caladium (Caladium $\times$ hortulanum). In: Plant \& Animal Genome Conference XXIV, San Diego, CA, January 9-13, 2016. https://pag.confex.com/pag/xxiv/webprogram/Paper20405.html. Accessed 12 Aug 2020

Cao Z, Deng Z, McLaughlin M (2014) Interspecific genome size and chromosome number variation sheds new light on species 
classification and evolution in Caladium (Araceae). J Am Soc Hortic Sci 49:449-459

Cao Z, Sui S, Cai X, Yang Q, Deng Z (2016) Somaclonal variation in 'Red Flash' caladium: morphological, cytological and molecular characterization. Plant Cell Tissue Organ Cult. https://doi. org/10.1007/s11240-016-0996-3

Chen J, Henny RJ (2008) Ornamental foliage plants: improvement through biotechnology. In: Kumar A, Sopory SK (eds) Recent advances in plant biotechnology and its applications. I.K. International Publishing House Pvt. Ltd., New Delhi, pp 140-156

Chen J, Henny RJ, Chao TC (2003) Somaclonal variation as a source for cultivar development of ornamental aroids. In: Pandalai SG (ed) Recent research development in plant science, vol 1. Research Signpost, Kerala, pp 31-43

Chu Y, Yazawa S (2001) The variation and the hereditary stability on leaf character of plantlets regenerated from micropropagation in caladium. J Chin Soc Hortic Sci 47:59-67

Datta SK (2014) Induced mutagenesis: basic knowledge for technological success. In: Tomlekova NB, Kozgar MI, Wani MR (eds) Mutagenesis: exploring genetic diversity of crops. Wageningen Academic Publishers, Wageningen, pp 97-129. https://doi. org/10.3920/978-90-8686-796-7_5

Datta SK, Teixeira da Silva JA (2006) Role of induced mutagenesis for development of new flower colour and type in ornamentals. In: Teixeira da Silva JA (ed) Floriculture, ornamental and plant biotechnology: advances and topical issues, vol 1470 vol I, 1st edn. Global Science Books Ltd., Isleworth, pp 640-645

Deng Z (2012) Caladium genetics and breeding: recent advances. Floricult Ornam Biotechnol 6(Special issue 1):53-61

Deng Z (2018) Caladium. In: Van Huylenbroeck J (ed) Ornamental crops. Handbook of plant breeding, vol 11. Springer, Cham, pp 273-299

Deng Z, Harbaugh BK (2006) Independent inheritance of leaf shape and main vein color in caladium. J Am Soc Hortic Sci 131:53-58

Deng Z, Harbaugh BK (2009) Leaf blotching in caladium (Araceae) is under simple genetic control and tightly linked to vein color. HortScience 44:40-43

Deng Z, Harbaugh BK, Peres NA (2007) 'UF-331' and 'UF-340': new dwarf caladium cultivars for landscape and pot plants. HortScience 43(7):2231-2235

Deng Z, Harbaugh BK, Peres NA (2011) 'UF-172', a pink fancy-leaved caladium cultivar for large containers and landscapes. HortScience 46(1): 132-134

Doležel J, Greilhuber J, Suda J (2007) Estimation of nuclear DNA content in plants using flow cytometry. Nat Protoc 2(9):2233-2244

Fulton TM, Chunwongse J, Tanksley SD (1995) Microprep protocol for extraction of DNA from tomato and other herbaceous plants. Plant Mol Biol Reptr 13:207-209

Gong L, Deng Z (2011) Development and characterization of microsatellite markers for caladiums (Caladium Vent.). Plant Breed 130(5):591-595

Grosser JW, Gmitter FG (2016) Improved sweet orange cultivars for processing and the fresh market. https://citrusrdf.org/wp-content/ uploads/2012/09/UF-Scions-New-Sweet-Oranges_Grosser-Gmitt er-CRDF-2017.pdf

Hartman RD, Zettler FW (1974) Effects of dasheen mosaic virus on yields of Caladium, Dieffenbachia, and Philodendron. Phytopathology 64:768

Heinz DJ, Krishnamurthi M, Nickell L, Maretzki A (1977) Cell, tissue and organ culture in sugarcane improvement. Applied and fundamental aspects of plant cell tissue organ culture. Springer, Berlin, pp 3-17
Henny R, Chen J, Norman D (2003) 'Diamond Bay' and 'Emerald Bay' Aglaonema. HortScience 38:1446-1447

Jain SM (2008) In vitro mutagenesis in banana (Musa spp.) improvement. In: IV International Symposium on Banana: International Conference on Banana and Plantain in Africa: Harnessing International. p 605-614

Krishna H, Alizadeh M, Singh D, Singh U, Chauhan N, Eftekhari M, Sadh RK (2016) Somaclonal variations and their applications in horticultural crops improvement. 3 Biotech 6:54. https://doi. org/10.1007/s13205-016-0389-7

Larkin P, Scowcroft W (1981) Somaclonal variation - a novel source of variability from cell cultures for plant improvement. Theor Appl Genet 60:197-214

Maas PG, Barutcu AR, Rinn JL (2018) Interchromosomal interactions: a genomic love story of kissing chromosomes. J Cell Biol 218:27-38

Maluszynski M, Ahloowalia BS, Sigurbjörnsson B (1995) Application of in vivo and in vitro mutation techniques for crop improvement. Euphytica 85:303-315

Manzoor A, Ahmad T, Bashir MA, Hafiz IA, Silvestri C (2019) Studies on colchicine induced chromosome doubling for enhancement of quality traits in ornamental plants. Plants 8:194

Murashige T, Skoog F (1962) A revised medium for rapid growth and bioassays with tobacco tissue cultures. Physiol Plant 15:473-497

Royal Horticultural Society (1986) RHS colour chart. Royal Horticultural Society, London

Selby C, Collin H (1976) Clonal variation in growth and flavor production in tissue cultures of Allium cepa L. Ann Bot 40:911-918

Sonnino A, Ancora G, Locardi C (1985) In vitro mutation breeding of potato. Nuclear techniques and in vitro culture for plant improvement. IAEA, Vienna, pp 385-389

Sunderland N (1977) Nuclear cytology. In: Street HE (ed) Plant cell and tissue culture, vol 2. University of California Press, Berkeley, pp 177-206

Swanson EB, Herrgesell MJ, Arnoldo M, Sippell DW, Wong RS (1989) Microspore mutagenesis and selection: canola plants with field tolerance to the imidazolinones. Theor Appl Genet 78:525-530

Thepsithar C, Thongpukdee A, Chiensil P (2010) Micropropagation of Caladium bicolor (Ait.) Vent. 'Thep Songil' and incidence of somaclonal variants. Acta Hortic 855:273-279

Thongpukdee A, Thepsithar C, Chiensil P (2010) Somaclonal variation of Caladium bicolor (Ait.) Vent. 'Jao Ying' after in vitro culture propagation. Acta Hortic 855:281-287

Trujillo I, Garcia E (1996) Strategies for obtaining somaclonal variants resistant to Yellow Sigatoka (Mycophaerella musicola). Informusa 5:12-13

Van Harten AM (1998) Mutation breeding: theory and practical applications. Cambridge University Press, Cambridge, p 279

Wilfret GJ (1993) Caladium. In: de Hertogh A, LeNard M (eds) The physiology of flower bulbs. Elsevier, Amsterdam, pp 239-247

Zhang Y, Chen J, Cao Y, Duan J, Cai X (2020) Induction of tetraploids in 'Red Flash' caladium using colchicine and oryzalin: morphological, cytological, photosynthetic and chilling tolerance analysis. Sci Hortic 272:109524. https://doi.org/10.1016/j.scienta.2020.109524

Publisher's Note Springer Nature remains neutral with regard to jurisdictional claims in published maps and institutional affiliations. 